\title{
A CPW - Fed Octagonal Ring Shaped Ultra Wide Band Antenna for Wireless Applications
}

\author{
Puneet Khanna $^{1}$, Amar Sharma ${ }^{1,2}$, A. K. Singh ${ }^{3}$, and Arun Kumar ${ }^{1,2,4}$ \\ ${ }^{1,2,4}$ Department of Electronics \& Communication Engineering, School of Engineering Technology, IFTM University, \\ Moradabad, India \\ ${ }^{3}$ Department of Electronics \& Instrumentation Engineering, F.E.T, Rohilkhand University, Bareilly, India
}

\begin{abstract}
A CPW - Fed octagonal ring shaped antenna for wideband operation is presented. The radiating patch of proposed octagonal ring antenna consists of symmetrical slot in place of conventional annular ring microstrip antenna. The ground plane consists of two rectangular slots. The radiator and the ground plane are on same plane that utilizes the space available around the radiator. The proposed antenna is simulated through Ansoft's High Frequency Structure Simulator (HFSS). Measured result shows balanced agreement with the simulated results. The prototype is taken with dimensions $47 \mathrm{~mm} \times 47 \mathrm{~mm} \times 1.6 \mathrm{~mm}$ that achieves good return loss, constant group delay and good radiation patterns over the entire operating bandwidth of 2.0 to 9.5 $\mathrm{GHz}(7.5 \mathrm{GHz})$. The proposed antenna achieves high impedance bandwidth of $130 \%$. Thus, the proposed antenna is applicable for $\mathrm{S}$ and $\mathrm{C}$ band applications.
\end{abstract}

\section{Introduction}

In today's wireless communication systems, there is a great demand of high data transmission rate [1]. Due to light weight, low cost and good performance wideband microstrip antennas play a major role for fulfilling these demands [2]. As a major component, the antennas with wideband properties are extensively investigated by the researchers. Designing of an efficient small size antenna for wideband applications is a challenging task. Wireless devices require an antenna with large impedance bandwidth and excellent radiation patterns over the entire band [3-5]. Printed microstrip patch antennas have been very useful because they can be easily integrated in complex circuits such as array of antennas, trident shape etc. [6, 7]. Several designs have been proposed by the researchers to achieve the wide bandwidth with suitable radiation characteristics such as octagonal antenna with modified ground plane [8, 9], microstrip square-ring slot antenna [10], compact rectangular patch antenna have been proposed for wideband applications [11], defected ground structure for WLAN/WiMAX [12], circular ring microstrip antenna [13], elliptical disc monopole antenna [14] and many other shapes and techniques are used for bandwidth enhancement [1518], while slot patch UWB CPW fed antenna [19] was designed for enhancing radiation performance at higher frequencies. For achieving UWB performance of antenna, researchers done a lot of work now days in this field [20-
21]. Metamaterial slot antenna is also an emerging technology for operating antennas at different frequencies [22]. Some researchers also work on triple band and multiband microstrip antennas [23]. This article presents a coplanar waveguide (CPW)-fed octagonal ring shape antenna for wireless applications. The antenna covers frequency band from 2.0 to $9.5 \mathrm{GHz}$, which is approximately $130 \%$ bandwidth. The performance of the proposed antenna is studied in terms of return loss, gain, delay and radiation patterns. Details of the antenna design and characteristics are discussed in next section. Section three covers the parametric study in detail while section four covers the experimental results and discussions. Section five concludes the discussions made earlier.

\section{Antenna Design}

Normally, the motivation of designing a wideband antenna is to design a small and simple antenna that has low distortion with large bandwidth. Figure 1 illustrates the proposed configurations of the antenna, which consists of an octagonal ring patch and a ground plane both on same side of the substrate. The overall size of the proposed antenna is $47 \mathrm{~mm} \times 47 \mathrm{~mm} \times 1.6 \mathrm{~mm}$. The proposed antenna is printed on one side of an FR-4 substrate of $1.6 \mathrm{~mm}$ thickness, with a relative permittivity of 4.4 and a loss tangent 0.024 as shown in Figure 2. The radiating patch of the proposed antenna consists of an octagonal ring with outer and inner radius of $R_{\mathrm{p} 1}$ and $R_{\mathrm{p} 2}$ and a microstrip feed line of width $W_{\mathrm{f}}$ and length $L_{\mathrm{p}}$. The ground plane is on the same plane as radiator with two rectangular slits each of which having dimension as $W_{\mathrm{g}}$ $\times L_{\mathrm{g}}$. The optimized values of all the parameters of the proposed octagonal ring microstrip antenna are mentioned in Table 1.

Table 1: Design parameters of the proposed octagonal ring microstrip antenna.

\begin{tabular}{cc}
\hline Parameters & Units (mm) \\
\hline$L$ & 47 \\
$W$ & 47 \\
$R_{\mathrm{p} 1}$ & 14.4 \\
$R_{\mathrm{p} 2}$ & 5 \\
$L_{\mathrm{p}}$ & 10.2 \\
$L_{\mathrm{g}}$ & 10 \\
$W_{\mathrm{g}}$ & 21.17 \\
$W_{\mathrm{f}}$ & 4.0 \\
$h$ & 1.6 \\
\hline
\end{tabular}


The above design skills are introduced to obtain wideband accomplished with good return loss, high impedance bandwidth and constant group delay over the entire operating band. Effect of changing the various parameters like variation of outer and inner radius, ground plane and the width of feed line on the performance of proposed antenna have been studied. Performance simulations of the proposed antenna were achieved by using electromagnetic solver, Ansoft's High Frequency Structure Simulator (HFSS) [24].

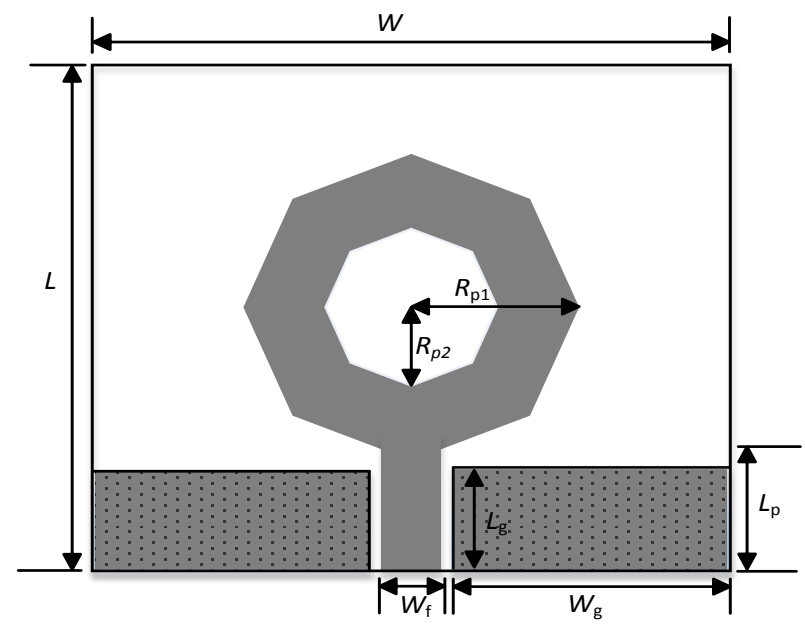

(a)

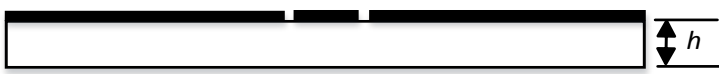

(b)

Figure 1: Schematic configuration of the proposed CPWfed octagonal ring shape ultra wideband microstrip antenna.

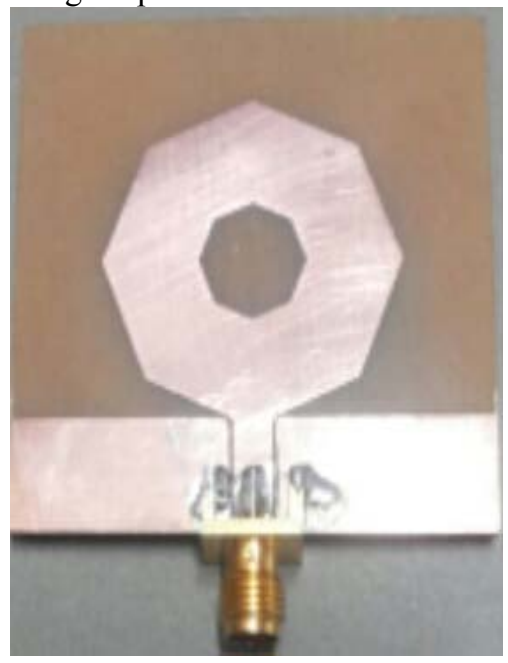

Figure 2: Photograph of the fabricated CPW- fed octagonal ring shape wideband antenna.

\section{Parametric Study}

A parametric study is done to understand the effects of various parameters and to optimize the performance of the proposed design. The effect of radius on the inner and outer rings $\left(R_{\mathrm{p} 1}\right.$ and $\left.R_{\mathrm{p} 2}\right)$, microstrip feed line $\left(L_{\mathrm{p}}\right.$ and $\left.W_{\mathrm{f}}\right)$, ground plane $\left(L_{\mathrm{g}}\right.$ and $\left.W_{\mathrm{g}}\right)$ of the octagonal ring are considered for optimization. Figure 3 shows the variation of the outer radius $R_{\mathrm{p} 1}$ of the octagonal ring from 14.0 to $14.8 \mathrm{~mm}$. The return loss remains less than $10 \mathrm{~dB}$ for the entire value of $R_{\mathrm{p} 1}$, but maximum bandwidth for the return loss is obtained for $R_{\mathrm{p} 1}=14.4 \mathrm{~mm}$. Hence $R_{\mathrm{p} 1}=14.4 \mathrm{~mm}$ is considered as optimum value for the operating band of 2.0 to $9.5 \mathrm{GHz}$. Figure 4 shows the effect of variation of inner radius $\left(R_{\mathrm{p} 2}\right)$ from 4.8 to $5.2 \mathrm{~mm}$. At $R_{\mathrm{p} 2}=4.8 \mathrm{~mm}$ it is found that the return loss does not provide adequate bandwidth. Further increase of $R_{\mathrm{p} 2}$ from 4.9 to $5.2 \mathrm{~mm}$, shows that the bandwidth for return loss less than $10 \mathrm{~dB}$ remains almost constant. However, the maximum value of return loss is obtained at $R_{\mathrm{p} 2}=5.0 \mathrm{~mm}$. Therefore, it is decided to take the value of $R_{\mathrm{p} 2}=5.0 \mathrm{~mm}$ as the optimum value for $R_{\mathrm{p} 2}$ for the entire operating bandwidth.

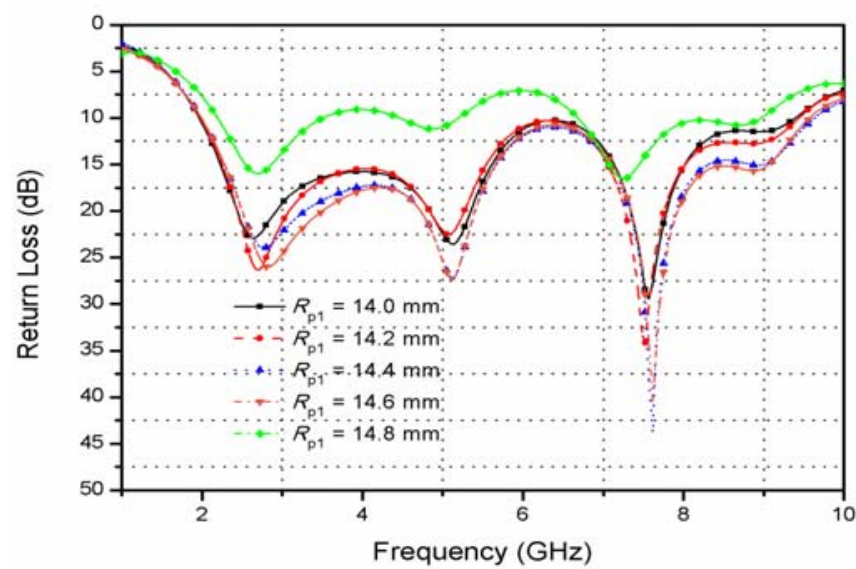

Figure 3: Simulated return loss against frequency for the octagonal ring shape ultra wideband antenna with various $R_{\mathrm{p} 1}$ : other parameters are the same as listed in Table 1 .

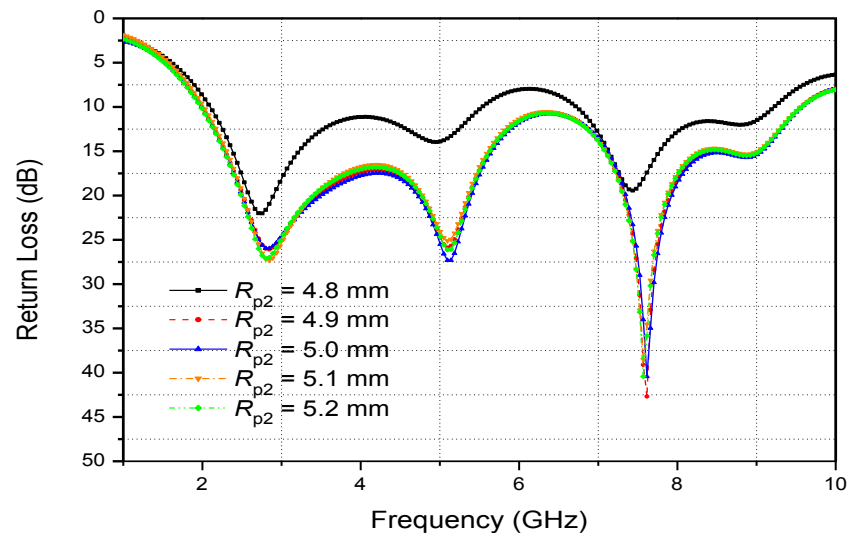

Figure 4: Simulated return loss against frequency for the octagonal ring shape ultra wideband antenna with various $R_{\mathrm{p} 2}$ : other parameters are the same as listed in Table 1 .

The effect of variation in ground length $\left(L_{\mathrm{g}}\right)$ of the proposed antenna on the return loss is illustrated in Figure 5. At $L_{\mathrm{g}}=$ $9.8 \mathrm{~mm}$ the higher band shifts towards lower band of frequency that decreases the desired bandwidth. At $L_{\mathrm{g}}=9.9$ $\mathrm{mm}$ the return loss is less at resonant frequency $7.14 \mathrm{GHz}$ 
while at $L_{\mathrm{g}}=10.0 \mathrm{~mm}$ the proposed antenna shows better return loss with desired bandwidth. After further increasing the value of $L_{\mathrm{g}}$ the return loss between 6 to $8 \mathrm{GHz}$ is not below $10 \mathrm{~dB}$ and does not covers the entire operating bandwidth (2.0 to $9.5 \mathrm{GHz}$ ). Therefore, it is decided to take $L_{\mathrm{g}}=10.0 \mathrm{~mm}$ as the optimum value of ground length for the entire operating band.

Figure 6 illustrates the effect of the microstrip feed line width $W_{\mathrm{f}}$ on the return loss of the proposed antenna. It is observed that by changing the value of $W_{\mathrm{f}}$ from 3.8 to 4.2 $\mathrm{mm}$ the impedance matching improves at 4 to $10 \mathrm{GHz}$ and degrades at $2.8 \mathrm{GHz}$. Therefore, it is decided to take $W_{\mathrm{f}}=$ $4.0 \mathrm{~mm}$ as the optimum value of feed width.

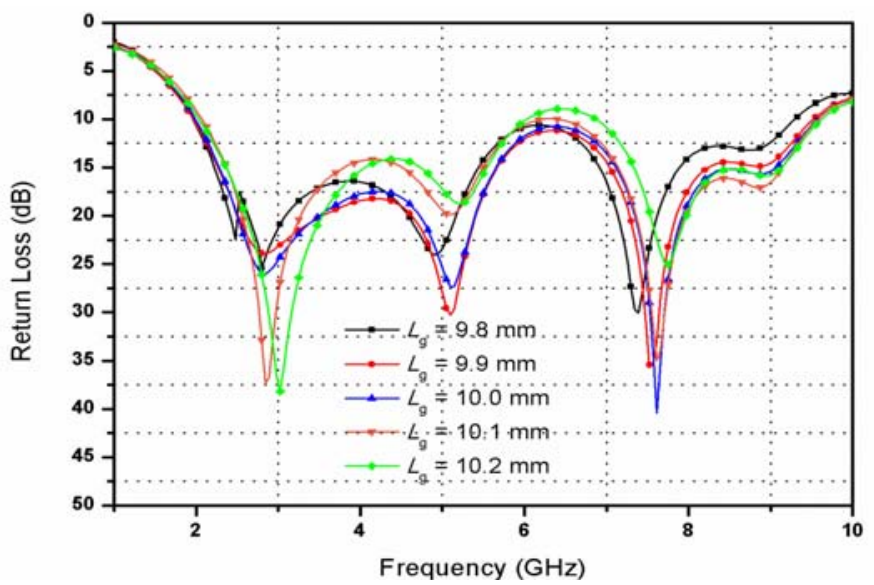

Figure 5: Simulated return loss against frequency for the octagonal ring shape ultra wideband antenna with various $L_{\mathrm{g}}$ : other parameters are the same as listed in Table 1.

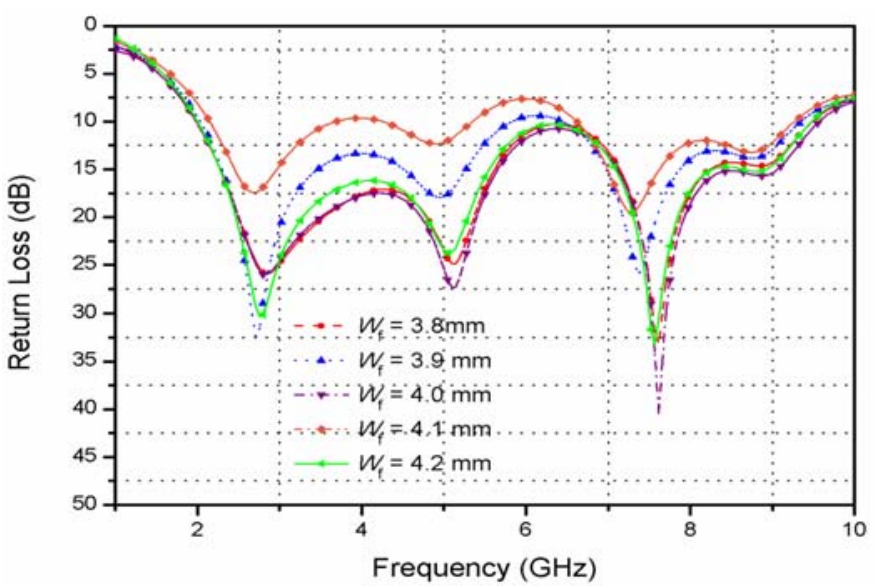

Figure 6: Simulated return loss against frequency for the octagonal ring shape ultra wideband antenna with various $W_{\mathrm{f}}$ : other parameters are the same as listed in Table 1 .

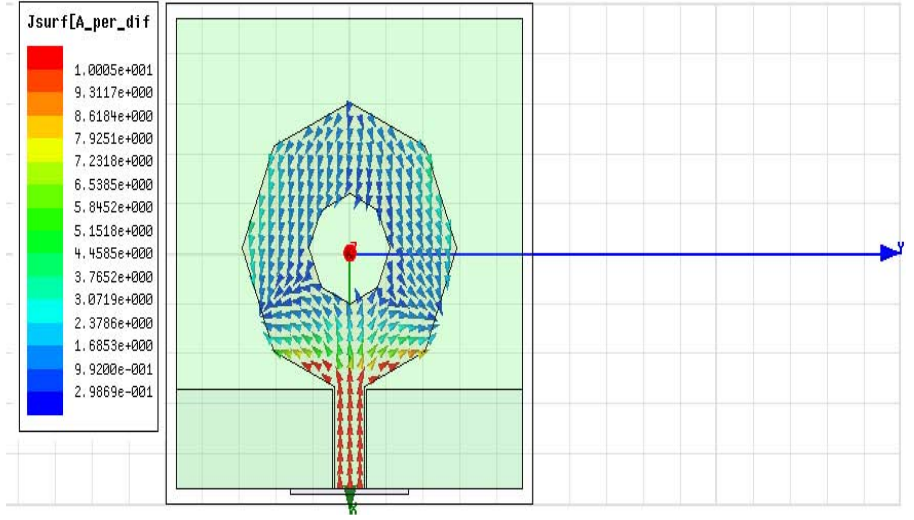

(a) $2.85 \mathrm{GHz}$

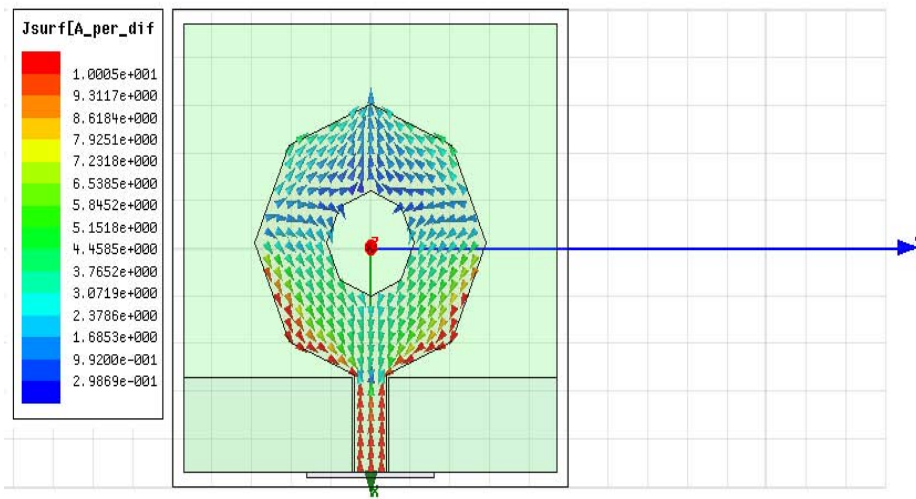

(b) $5.14 \mathrm{GHz}$

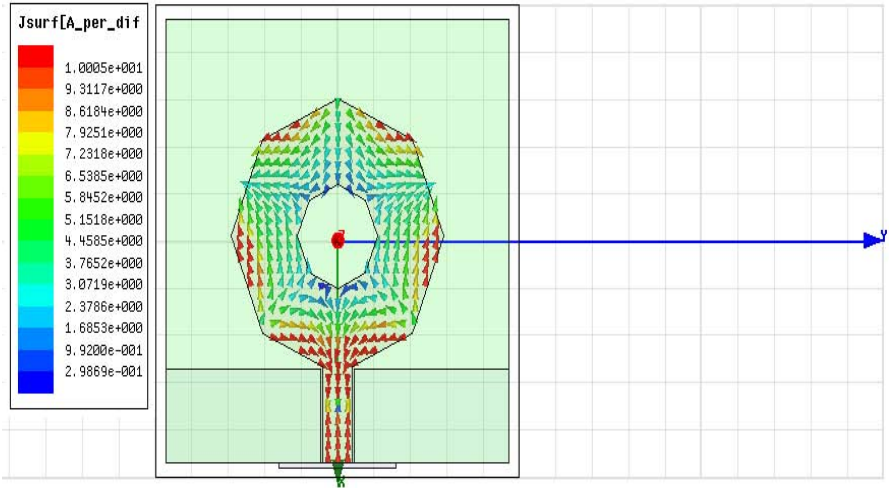

(c) $7.61 \mathrm{GHz}$

Figure 7: The surface current distribution of the proposed octagonal ring shape ultra wideband antenna at (a) $2.85 \mathrm{GHz}$, (b) $5.14 \mathrm{GHz}$, and (c) $7.61 \mathrm{GHz}$.

The simulated surface current distributions on resonant frequencies of $2.85 \mathrm{GHz}, 5.14 \mathrm{GHz}$, and $7.61 \mathrm{GHz}$ are shown in Figure 7. When the microstrip patch antenna is provided with power, a charge distribution appears on the upper and lower part of the patch, as well as on the ground plane. Due to this charge distribution the current will flow at the top and bottom surface of the patch. From this closed analysis of the surface current distribution of the proposed antenna it is found out that at $2.85 \mathrm{GHz}, 5.14 \mathrm{GHz}$, and 
7.61 GHz resonant frequency the proposed antenna resonates in TM11 mode, TM21 mode, TM12 mode, respectively.

Figure 8 illustrates the effect of the gap between ground plane and feed line on the return loss of the proposed antenna. It is observed that by changing the value from 0.32 $\mathrm{mm}$ to $0.34 \mathrm{~mm}$ the impedance matching improves. Therefore, it is decided to take the gap between them as 0.33 $\mathrm{mm}$.

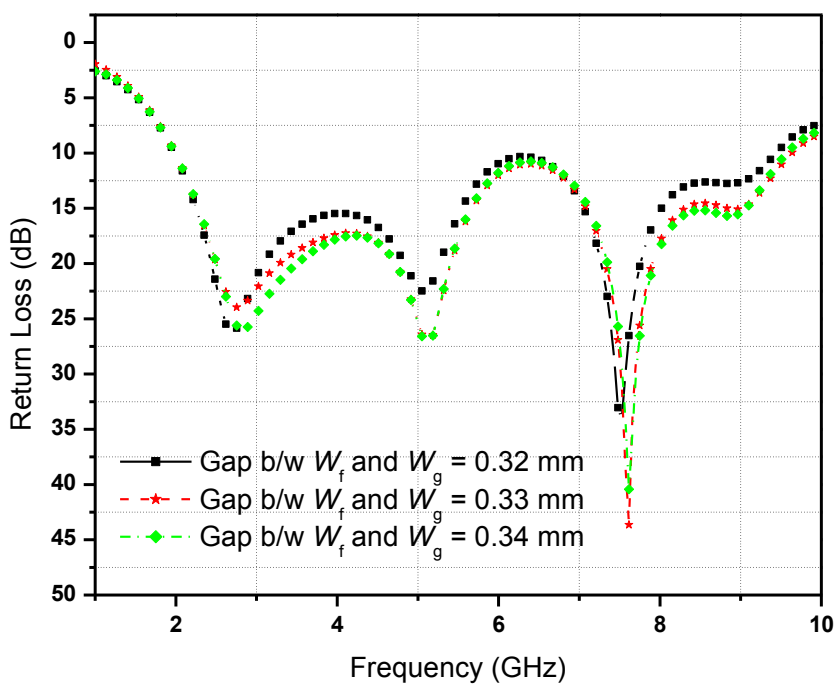

Figure 8: Simulated return loss against frequency for the octagonal ring shape ultra wideband antenna for the gap between ground plane and feed line: other parameters are the same as listed in Table 1.

\section{Experimental Results and Discussions}

The performances of the proposed antenna such as return loss, group delay and radiation pattern are measured using Agilent $8757 \mathrm{E}$ vector analyzer. The measured and simulated return loss curve of the CPW-fed octagonal ring wideband antenna is shown in Figure 9. There is a good agreement between simulated and measured results. The small difference between measured and simulated result is due to the effect of SMA connector soldering and fabrication tolerance. The designed antenna offers a impedance bandwidth of $130 \%$ (2.0 to $9.5 \mathrm{GHz})$ which meets the bandwidth requirements of $\mathrm{S}$ and $\mathrm{C}$ band.

The proposed antenna produces good radiation patterns characteristics as shown in Figure 10(a)-10(c). The radiation patterns illustrated in $\mathrm{H}$ - and E- planes are at sampling frequencies of $2.85,5.14$ and $7.61 \mathrm{GHz}$ respectively. The radiation patters at higher frequencies are distorted because the ground plane is a part of loop path, the surface current on the radiating plane changes the effective current distribution of the loop and results in distortion.

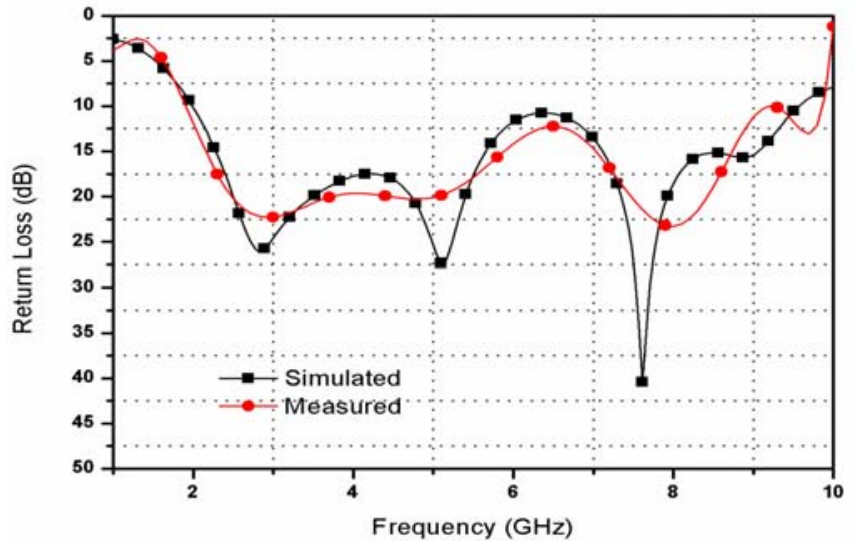

Figure 9: Simulated and measured return loss against frequency for the octagonal ring shape wideband antenna.
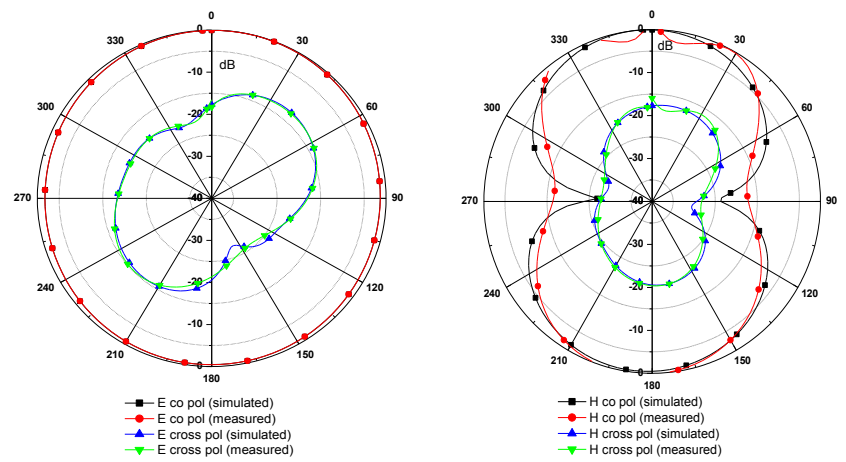

(a)
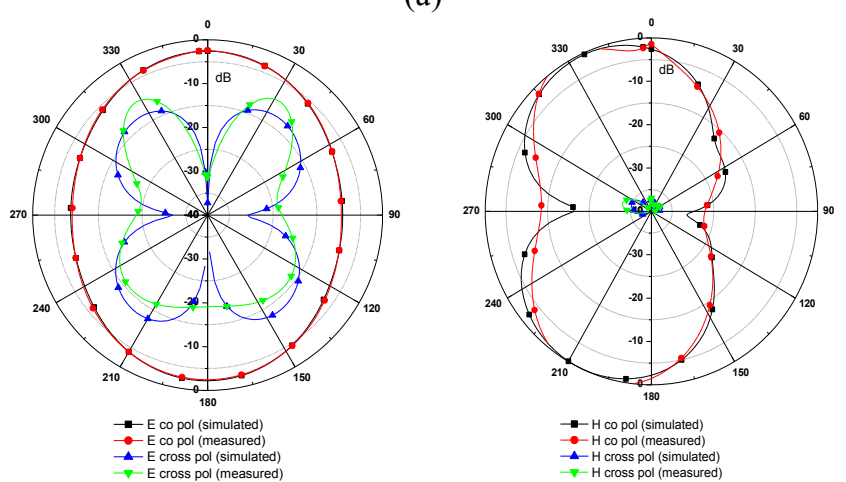

(b)
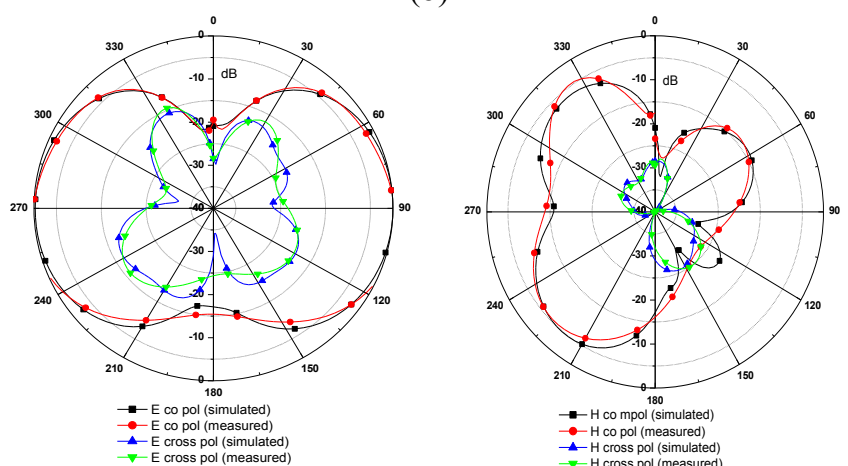

(c)

Figure 10: Radiation patterns at various frequencies of octagonal ring shape wideband antenna (a) $2.85 \mathrm{GHz}$ (b) $5.14 \mathrm{GHz}$ and (c) $7.61 \mathrm{GHz}$. 
These patterns are suited for application in almost all wireless communication equipment, as expected. It is also observed that simulated results show a good agreement with measured results.

The antenna gain variation with frequency is shown in Figure 11 for the proposed antenna. Antenna gain varies from -1 to $3.5 \mathrm{dBi}$ over the entire operating band. Simulated result of gain shows good agreement with the measured results.

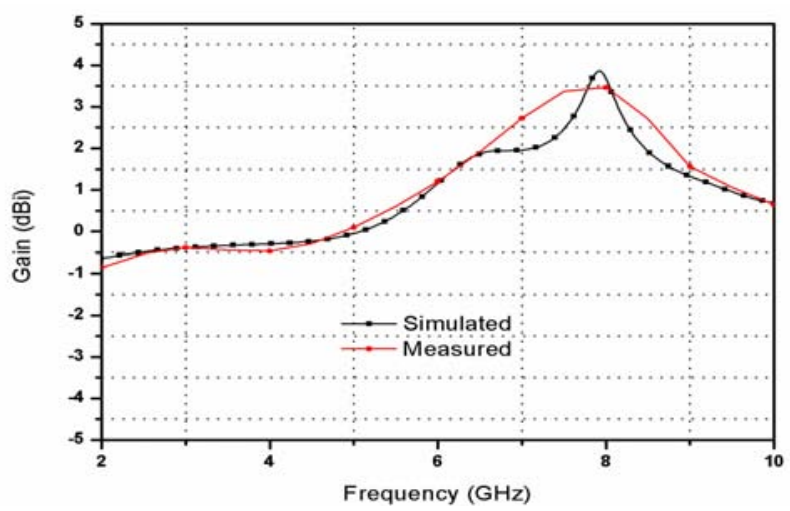

Figure 11: Simulated and measured gain against frequency for the octagonal ring shape wideband antenna.

Table 2: Comparison between the proposed antenna and some other existing wideband antennas

\begin{tabular}{|c|c|c|c|c|c|}
\hline $\begin{array}{l}\text { Refer } \\
\text { ence }\end{array}$ & $\begin{array}{l}\text { Overall } \\
\text { dimensi } \\
\text { ons }\end{array}$ & $\begin{array}{c}\text { Frequenc } \\
\text { y Range } \\
(\mathrm{GHz})\end{array}$ & $\begin{array}{c}\text { Impe } \\
\text { dance } \\
\text { Band } \\
\text { width } \\
(\%)\end{array}$ & $\begin{array}{l}\text { Gain } \\
(\mathrm{dBi})\end{array}$ & $\begin{array}{c}\text { Applica } \\
\text { tion }\end{array}$ \\
\hline [12] & $\begin{array}{c}38 \times 25 \times \\
1.6\end{array}$ & $1.2-4.5$ & 86.71 & 2.85 & $\begin{array}{l}\text { WLAN/ } \\
\text { WiMax }\end{array}$ \\
\hline [25] & $\begin{array}{c}35 \times 35 \times \\
1.6\end{array}$ & $\begin{array}{c}2.65- \\
9.37\end{array}$ & 112 & 4.5 & General \\
\hline [26] & $\begin{array}{c}60 \times 30 \times \\
1.6\end{array}$ & $1.2-4.5$ & 115 & 2.2 & General \\
\hline [27] & $\begin{array}{c}25 \times 25 \times \\
1.6\end{array}$ & $\begin{array}{c}2.96- \\
7.95\end{array}$ & 91.47 & 7.3 & $\begin{array}{c}\mathrm{S} \text { and } \mathrm{C} \\
\text { Band }\end{array}$ \\
\hline [28] & $\begin{array}{c}120 \times 80 \\
\times 9.0\end{array}$ & $\begin{array}{c}1.56- \\
2.12\end{array}$ & 30.5 & 9.86 & $\begin{array}{c}\text { Improve } \\
\text { d } \\
\text { Bandwi } \\
\text { dth }\end{array}$ \\
\hline [29] & $\begin{array}{c}50 \times 50 \times \\
1.57\end{array}$ & $5.0-7.0$ & 33.52 & $\begin{array}{c}\text { Not } \\
\text { Given }\end{array}$ & $\begin{array}{c}\text { Wireles } \\
\text { s } \\
\text { Devices }\end{array}$ \\
\hline $\begin{array}{l}\text { Propo } \\
\text { sed } \\
\text { Anten } \\
\text { na }\end{array}$ & $\begin{array}{c}47 \times 47 \times \\
1.6\end{array}$ & $2.0-9.5$ & 130 & 3.5 & $\begin{array}{c}\mathrm{S} \text { and } \mathrm{C} \\
\text { band }\end{array}$ \\
\hline
\end{tabular}

Table 2 shows a comparative study between the proposed antenna and some existing wideband antennas. The tabulated data clearly shows that the proposed antenna has highest frequency range and efficiency among other antennas having approximate similar dimensions. The proposed antenna covers the total $\mathrm{S}$ band ( 2 to $4 \mathrm{GHz}$ ) and $\mathrm{C}$ band ( 4 to $8 \mathrm{GHz}$ ), so it is best suited for these bands.

Figure 12 illustrates the group delay of the proposed antenna. Group delay is an important parameter in the designing of wideband antenna as it shows about the distortion of the transmitted pulses in the wireless communication. It is observed that the group delay for the proposed antenna is constant and less than $1 \mathrm{~ns}$ for entire operating bandwidth (2.0 to $9.5 \mathrm{GHz})$. For distortion less transmission, group delay should be less than $1 \mathrm{~ns}$ in the wideband antenna.

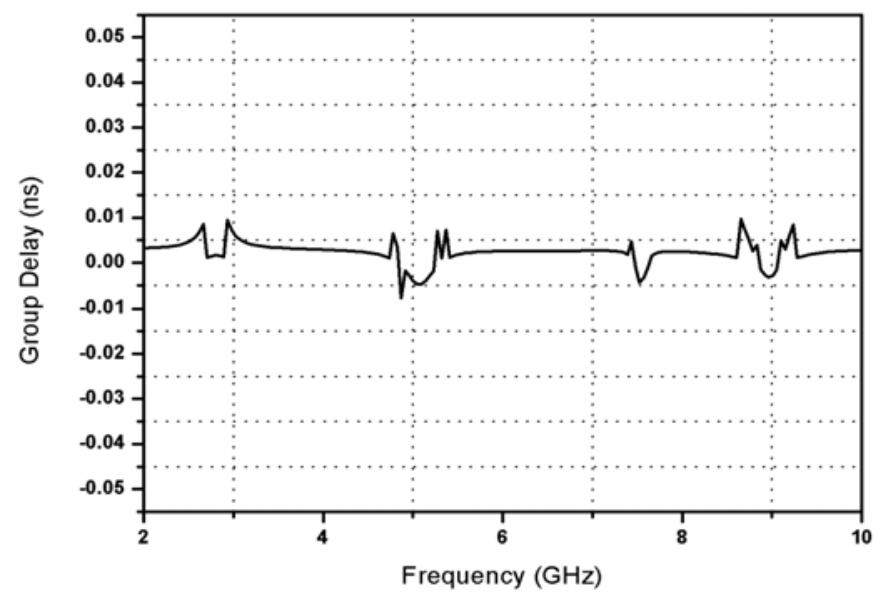

Figure 12: Group delay for the proposed octagonal ring shape wideband antenna.

\section{Conclusions}

A CPW-Fed octagon ring shape wideband microstrip antenna is presented in this study. The proposed antenna shows wideband performance in the frequency band of 7.5(2 to $9.5 \mathrm{GHz}$ ) for return loss less than $10 \mathrm{~dB}$. The simulated and measured results of the proposed antenna show a balanced agreement in terms of return loss, antenna gain and radiation patterns. The radiation patterns are satisfactory over the entire operating bandwidth. Also, almost constant group delay is achieved. The proposed antenna gave impedance bandwidth of about $130 \%$, this allows its use in various wireless applications.

\section{References}

[1] R. Azim, M.T Islam, N. Misran, "Microstrip line fed printed planar monopole antenna for UWB applications," Springer Arab Journal Sci Eng, 38: 2415-2422, 2013.

[2] K. Kamakshi, J.A. Ansari, A. Singh, M. Aneesh, A.K. Jaiswal, "A novel Ultrawideband toppled trapezium shaped patch antenna with partial ground plane," Microwave Optical Technology Letters, 57: 1983-1986, 2015.

[3] J. W. Shin, S. K. Hong, J. H. Choi, "A compact internal UWB antenna for wireless USB dongle applications," Microwave Optical Technology Letters, 50: 1643-1646, 2008.

[4] M. J. Ammann, Z. N. Chen, "A wide-band shorted planar monopole with bevel," IEEE Trans. Antennas Propag., 51: 901-903, 2003. 
[5] S. W. Su, K. L. Wong, C. L. Tang, "Ultra-wideband square planar monopole antenna for IEEE 802.16a operation in the 2-11-GHz band," Microwave Optical Technology Letters, 42: 463-466, 2004.

[6] K. L. Wong, C. H. Wu, S. W. Su, "Ultrawideband square planar metal-plate monopole antenna with a trident shaped feeding strip," IEEE Trans. Antennas Propag., 53: 12621269, 2005.

[7] C.H. Hsu, C.H. Chang, C.F. Tseng, P.C. Yang, W.E. Chen, C.H. Lai, J.S. Lin, H.W. Yang, "Planar octagon monopole antenna for UWB applications," Electromagnetic Field Problems and Applications (ICEF), IEEE Sixth Int. Conference, Dalian, Liaoning, 2012.

[8] M. Bitchikh, R. Aksas, A. Azrar, H. Kimouche, "A 2.3$14 \mathrm{GHz}$ UWB planar octagonal antenna with modified ground plane," Microwave Optical Technology Letters, 55: 479-482, 2013.

[9] T. Hariyadi, "A coplanar waveguide (CPW) wideband octagonal microstip antenna," IEEE Conference, Bandung (Indonesia), March 20-22, 2013.

[10] S. Sadat, M. Fardis, F. Geran, G. Dadashzadeh, "A compact microstrip square-ring slot antenna for UWB applications," Progress Electromagnetics, 67: 173-179. 2007.

[11] K. Baskaran, L.C. Ping, C.K. Chakrabarty, "A compact microstrip antenna for ultra wideband applications," European Journal Science, 67: 45-51, 2011.

[12] A.K. Gautam, A. Bisht, B.K. Kanaujia, "A wideband antenna with defected ground plane for WLAN/WiMAX applications," Elsevier Int. Journal of Electron and Comm, 70:354-358, 2015.

[13] Y. Seo, H. Lee, Y. Lim, "Design of a circular ring monopole antenna with inverted T-strip line for dual band operation," Microwave Optical Technology Letters, 55: 2174-2178, 2013.

[14] A.A. Adan, S.K.A. Rahim, K.G. Tan, A.W. Reza, "Design of 3.1-12 GHz printed elliptical disc monopole antenna with half circular modified ground plane for UWB application," Wireless personal communication, 69: 535549, 2013.

[15] Y.Y. Sun, S.W. Cheung, T.I. Yuk, "Design of a very compact UWB monopole antenna with microstrip fed," Microwave Optical Technology Letters, 55: 2232-2236. 2013.

[16] J.W. Zang, X.T. Wang, "Design and analysis of a compact ultra wideband antenna with a band notch characteristic," Microwave Optical Technology Letters, 55: 2236-2240, 2013.

[17] R. Chandel, A.K Gautam, B.K. Kanaujia, "A compact rombus-shaped slot antenna fed by microstrip-line for UWB applications," International Journal of Microwave and Wireless Technologies, 9: 4013-409, 2017.

[18] A. Agarwal, P.K. Singhal, A. Jain, Design and optimization of a microstrip patch antenna for increased bandwidth, 5: 529-535, 2013.

[19] A. Edalati, W. Shao, T. McCollough, "A novel cavity backed monopole antenna with UWB unidirectional radiation," Progress in Electromagnetic Research C, 72: 113. 2017.
[20] A.Y. Modi, N. Pisharody, J. Mehta, "A novel design of directive ultra wide band (UWB) triangular sheet antenna," Int. Conf. Communication Systems and Network Technologies, Gwalior, India, April 13, 2013, 29-32, 2013.

[21] J. Yang, A. Kishk, "A novel low-profile compact directional ultra-wideband antenna: the self-grounded bowtie antenna," IEEE Trans. Antennas Propag., 60 (3): 12141220, 2012.

[22] T. Ali, A. M. Saadh, R. C. Biradar, J. Anguera, and A. And'ujar, "A miniaturized metamaterial slot antenna for wireless applications," AEU-International Journal of Electronics and Communications, 82: 368-382, 2017.

[23] T. Ali, and R. C. Biradar, "A triple-band highly miniaturized antenna for WiMAX/WLAN applications," Microwave and Optical Technology Letters, 60 (2): 466471, 2018.

[24] Ansoft Corporation, Ansoft High-Frequency Structure Simulator (HFSS) version 14.0, Ansoft Corporation, Pittsburgh, PA.

[25] R.K. Sharan, S.K. Sharma, A. Gupta, \& R.K. Chaudhary, "An edge tapered rectangular patch antenna with parasitic stubs and slot for wideband applications, Wireless Personal Communication," 86: 1213-1220, 2016.

[26] C.L. Tsai, \& C.L. Yang, "Novel compact eye shaped UWB antennas," IEEE Antennas and Wireless Propagation Letters, 11: 184-187, 2012.

[27] P. Khanna, A. Sharma, K. Shinghal, A. Kumar, "A defected structure shaped CPW-fed wideband microstrip antenna for wireless applications," Hindawi, Journal of Engineering, Article ID 2863508, 1-7, 2016.

[28] K. Kamakshi, A. Singh, M. Aneesh, J.A. Ansari, "Novel design of microstrip antenna with improved bandwidth," Hindawi, International Journal of Microwave Science and Technology, 1-7, 2014.

[29] H.F. Abutarboush, R. Nilavalan, S.W. Ceung, K.M. Nasr, T. Peter, D. Budimir, H. Al-Raweshidy, "A reconfigurable wideband and multiband antenna using dualpatch elements for compact wireless devices," IEEE Trans. Antennas and Propagation, 60: 36-43, 2012. 